Article

\title{
High-Level Production of Bacteriotoxic Phospholipase A1 in Bacterial Host Pseudomonas fluorescens via ABC Transporter-Mediated Secretion and Inducible Expression
}

\author{
Jiyeon Park ${ }^{1,2,+}$, Gyeong Tae Eom ${ }^{3,+}$, Joon Young Oh ${ }^{4}{ }^{\oplus}$, Ji Hyun Park ${ }^{4}$, Sun Chang Kim ${ }^{2,5}$, \\ Jae Kwang Song ${ }^{4}$ and Jung Hoon Ahn ${ }^{1,5, * \mathbb{D}}$ \\ 1 Korea Science Academy of Korea Advanced Institute of Science and Technology, Busan 47162, \\ Korea; jyp131@kaist.ac.kr \\ 2 Intelligent Synthetic Biology Center, 291 Daehak-ro, Yuseong-gu, Daejeon 305-701, Korea; sunkim@kaist.ac.kr \\ 3 Research Center for Bio-based Chemistry, Korea Research Institute of Chemical Technology (KRICT) 1, \\ Ulsan 44429, Korea; eomgt@krict.re.kr \\ 4 Research Center for Bio-based Chemistry, Korea Research Institute of Chemical Technology (KRICT), \\ Daejeon 34114, Korea; jyoh@krict.re.kr (J.Y.O.); jhpark2@krict.re.kr (J.H.P.); ajee0414@gmail.com (J.K.S.) \\ 5 Department of Biological Sciences, Korea Advanced Institute of Science and Technology, \\ Daejeon 34141, Korea \\ * Correspondence: hoony@kaist.ac.kr; Tel.: +82-51-606-2335 \\ + These authors contributed equally to this work.
}

Received: 6 January 2020; Accepted: 9 February 2020; Published: 11 February 2020

\begin{abstract}
Bacterial phospholipase A1 (PLA1) is used in various industrial fields because it can catalyze the hydrolysis, esterification, and transesterification of phospholipids to their functional derivatives. It also has a role in the degumming process of crude plant oils. However, bacterial expression of the foreign PLA1-encoding gene was generally hampered because intracellularly expressed PLA1 is inherently toxic and damages the phospholipid membrane. In this study, we report that secretion-based production of recombinant PlaA, a bacterial PLA1 gene, or co-expression of PlaS, an accessory gene, minimizes this harmful effect. We were able to achieve high-level PlaA production via secretion-based protein production. Here, TliD/TliE/TliF, an ABC transporter complex of Pseudomonas fluorescens SIK-W1, was used to secrete recombinant proteins to the extracellular medium. In order to control the protein expression with induction, a new strain of P. fluorescens, which had the lac operon repressor gene lacI, was constructed and named ZYAI strain. The bacteriotoxic PlaA protein was successfully produced in a bacterial host, with help from ABC transporter-mediated secretion, induction-controlled protein expression, and fermentation. The final protein product is capable of degumming oil efficiently, signifying its application potential.
\end{abstract}

Keywords: phospholipase A1 (PLA1); PlaA, ABC transporter; Pseudomonas fluorescens; protein secretion

\section{Introduction}

Phospholipase A1 (PLA1) (EC 3.1.1.32) hydrolyzes the sn-1 acyl ester bonds in phosphoglycerides, forming fatty acids and lysophospholipids [1]. Several PLA1-encoding genes from microorganisms, such as Serratia sp. MK1 [2], Aspergillus oryzae [3], Escherichia coli [4], and Serratia liquefaciens [5], have been cloned and expressed. In the last decade, there has been a great interest in the commercial use of PLA1 for food, nutraceuticals, pharmaceuticals, and oil degumming [6,7]. Lysophospholipids, produced by the hydrolytic action of PLA1, can be used as surfactants and functional ingredients 
in foods, cosmetics, and pharmaceutical products [8]. The PLA1-mediated enzymatic degumming process, which converts nonhydratable phospholipids to hydratable lysophospholipids in renewable oils, has been suggested as an efficient and environment-friendly alternative to conventional chemical processes $[6,9,10]$.

Bacterial PLA1 is not well understood, and no crystal structure exists for any true PLA1 [1]. Minimal information is available on bacterial PLA1 due to the lack of any efficient method to clone, express, purify, and characterize the enzyme via large-scale cultivation. Bacteria use PLA1 as a virulence factor to invade the host cell, but it can also destroy their own membrane [11] and bacterial cell physiology [2,12]. Therefore, devising a method to mass-produce a bacterial PLA1 enzyme efficiently has significant importance in the industrial field. We chose plaA, a PLA1 gene from the Gram-negative bacterium Serratia sp. MK1, as the model bacterial PLA1 enzyme for our experiments.

According to a previous study, PlaA can be expressed in E. coli, but most of the recombinant PlaA accumulates in the cytoplasm of the E. coli cells [2]. Since PlaA is toxic to the expression host cells because it hydrolyzes the cell membrane's phospholipid, this study hypothesized that toxic PlaA could be produced more effectively by secreting it to the extracellular medium. To this end, PlaA was introduced into Pseudomonas fluorescens, which carries an ATP-binding cassette (ABC) transporter capable of secreting a variety of recombinant proteins, provided that they are fused with an $\mathrm{ABC}$ transporter signal sequence. In addition, $P$. fluorescens has several advantageous features as an expression host for recombinant protein production, such as its safety $[13,14]$, adequacy for high cell density culture [15,16], and its exploitable export system [17]. Specifically, it has an ABC transporter complex TliDEF that functions in hydrolase enzyme secretion [18] and can be supplemented with additional copies of tliDEF genes to enhance recombinant protein secretion [17]. The P. fluorescens ABC transporter, TliDEF, is composed of three different protein multimers: TliD, TliE, and TliF, wherein TliD is an ATP binding cassette (ABC), TliE a membrane fusion protein (MFP), and TliF an outer membrane factor (OMF) [18]. TliDEF recognizes a C-terminal signal polypeptide sequence, LARD3, which exists in the cargo proteins. By fusing LARD3 with the target proteins, TliDEF can be used to export the recombinant target proteins. Using the TliDEF ABC transporter, we expected to translocate PlaA immediately after its initial synthesis in the cytoplasm. This way, PlaA would no longer exert any significant influence on the cellular membrane biogenesis and physiology. In addition, the extracellular secretion-based production simplifies the purification steps because it removes the need for the energy-costly cell lysis step, and then the culture supernatant is made free of the cytosolic contaminant proteins.

\section{Materials and Methods}

\subsection{Bacterial Strains, Growth Conditions}

All genetic manipulations were performed with Escherichia coli XL1-Blue. The expression of each vector was conducted using E. coli XL1-Blue, Pseudomonas fluorscens $\Delta$ tliA $\Delta p r t A$ (P. fluorescens $\Delta t p$ ) [19], and P. fluorescens $\Delta t$ tiA $\Delta$ prtA algD::lacZYAI (P. fluorescens ZYAI) as the host strain. While E. coli XL1-Blue was cultured in a LB medium with $60 \mu \mathrm{g} / \mathrm{mL}$ kanamycin at $37^{\circ} \mathrm{C}, P$. fluorscens was cultured in a LB or M9 medium with $60 \mu \mathrm{g} / \mathrm{mL}$ kanamycin at $25^{\circ} \mathrm{C}$. We used a slightly modified recipe for the $\mathrm{M} 9$ medium, which consists of an ordinary concentration of $\mathrm{M} 9$ salts, $2 \mathrm{mM} \mathrm{MgSO}_{4}, 5 \%$ glycerol, trace elements (TE), and $0.1 \mathrm{mM} \mathrm{CaCl}_{2}$. TE was diluted from a $100 \times \mathrm{TE}$ stock solution, which was prepared as follows: $13.4 \mathrm{mM}$ EDTA, $3.1 \mathrm{mM} \mathrm{FeCl}{ }_{3}, 0.62 \mathrm{mM} \mathrm{ZnCl} 2,76 \mu \mathrm{M} \mathrm{CuCl}_{2}, 42 \mu \mathrm{M} \mathrm{CoCl}_{2}$, $162 \mu \mathrm{M} \mathrm{H}_{3} \mathrm{BO}_{3}$, and $8.1 \mu \mathrm{M} \mathrm{MnCl}_{2}$. The growth of $E$. coli harboring different plasmids was calculated from measured $A_{600}$ values based on logistic cell growth curves, where the initial absorbance of each culture tube was set to be the same value by diluting the overnight culture. 


\subsection{Construction of Plasmids}

The plaA and plaS genes (GenBank U37262) were amplified from Serratia sp. MK1 (KCTC 2865 from Korea Collection for Type Cultures) genomic DNA [20] and inserted into pDART, which carries the $\mathrm{ABC}$ transporter genes, as well as a C-terminal signal sequence gene, fused to the multiple cloning sites of the original vector pDSK519 [17]. We added codons of a His-tag at the $3^{\prime}$ end position of the plaA gene via a tagged PCR primer for detection, and a ribosomal binding site was inserted in the $5^{\prime}$ end. The pDART vector has genes coding for the $t l i D / t l i E / t l i F$ and a lipase $A B C$ transporter recognition domain 3 (LARD3). To make pDART-PlaA (pABC/PlaA) and pDART-PlaA/PlaS (pABC/PlaA/PlaS), the sequence coding for His-tagged PlaA cleaved with XbaI and KpnI was inserted into pDART (pABC). The PCR-amplified plaS was inserted into $\mathrm{pABC/PlaA}$, along with its original ribosomal binding site (RBS), using the In-Fusion cloning kit (Takara, Japan). As a control group, pPlaA was constructed by removing the $\mathrm{ABC}$ transporter genes from $\mathrm{pABC} / \mathrm{PlaA}$ using $\mathrm{BsrGI}$ and ligation (no $\mathrm{ABC}$ transporter genes but $C$-terminally fused signal sequence is retained). As another control experiment, amplified plaA was cleaved with SphI and KpnI and then ligated with pDSK519, resulting in pDSK-PlaA (no $\mathrm{ABC}$ transporter genes, no signal sequence). From here, the plaS was amplified, along with its original RBS, cleaved with XbaI and SacI, and then ligated with pDSK-PlaA, resulting in pDSK-PlaA/PlaS. The transformed colonies were isolated on LB plates containing $30 \mu \mathrm{g} / \mathrm{mL}$ kanamycin and lecithin (L- $\alpha$-phosphatidylcholine from egg yolk, Merck, Germany) to check PlaA activity. We followed the standard protocols for plasmid isolation, restriction endonuclease digestion, ligation, polymerase chain reaction (PCR), and gel electrophoresis procedures [21]. E. coli transformation was performed using conventional heat shock methods, and $P$. fluorescens transformation was performed via electroporation at $2.5 \mathrm{kV}, 125 \Omega$, and $50 \mu \mathrm{F}$ with electrocompetent cells [17] or via conjugation [22].

\subsection{Construction of P. fluorescens ZYAI and P. fluorescens AlgD::LacI}

The $\operatorname{lacl}^{q}$ gene was amplified from pBB528 [23] using lacI primers such that the promoter and transcription terminator of $\operatorname{lac} I^{q}$ were contained in the PCR fragment. The algD upstream part (algD1) was also amplified using algD1 primers such that the stop codon and the transcription terminator for the $\operatorname{alg} D$ operon were contained in the PCR fragment. The algD downstream part (algD2) was amplified using algD2 primers. These three PCR fragments and pK19 mobsacB [24] were combined to make $\mathrm{pK}$-lacI using an In-Fusion cloning kit. The lac operon (including a promoter, an operator, lacZ, lacY, and lacA) was amplified, using lacZYA primers, and inserted into $\mathrm{pK}$-lacI using restriction enzyme sites HindIII and PstI. The resulting pK-lacI and pK-lacIZYA plasmid were transformed into E. coli S17-1 for conjugal transfer into P. fluorescens $\Delta t p$. The P. fluorescens $\Delta t p$ with the inserted lacI or lac operon was screened as previously reported [19]. Single recombinants were screened on M9 containing $0.6 \%$ lactose to check the activity of the lac operon. The colonies of the single recombinants were grown in 10\% sucrose, and double recombinants were then screened on $10 \%$ sucrose-LB plates. The sequences of all primers used in this study are presented in Table 1. 
Table 1. List of primers used in this study.

\begin{tabular}{|c|c|c|}
\hline Primer ID & Primer Sequence for PCR & $\begin{array}{l}\text { Target } \\
\text { Vector }\end{array}$ \\
\hline lacI & $\begin{array}{l}\text { F 5' GCGGGGTTTTTTTTTAAGGCAGTTATTGGTCCCT 3' } \\
\text { R 5' AAAAAGCCGCCAGCGGAACTGGCGGCGTGTGAAATTGTTATCCGCTC 3' }\end{array}$ & pK19 \\
\hline algD1 & $\begin{array}{l}\text { F 5' GACGGCCAGTGAATTCCACGAAGTGGTCGGCGTAGA3' } \\
\text { R 5' AAAAAAAAACCCCGCCGAAGCGGGGTCAGTCGACGCCGGCTTTCTTGC3' }\end{array}$ & pK19 \\
\hline $\operatorname{algD2}$ & $\begin{array}{l}\text { F 5' CGCTGGCGGCTTTTTTCCCAGTACTACATGCGCCC3' } \\
\text { R 5' TGATTACGCCAAGCTGTTGAGCAGGGACGACACGT3' }\end{array}$ & pK19 \\
\hline lacZYA & $\begin{array}{l}\text { F 5' GGG AAGCTTGCGCAACGCAATTAATGTGAG 3' } \\
\text { R 5' GGGCTGCAGGGTCAAAGAGGCATGATGCG 3' }\end{array}$ & pK-lacI \\
\hline plaA-1 & $\begin{array}{l}\text { F 5' TCTAGA ATGAGTATGTCTTTGAGTTTTAC } 3^{\prime} \\
\text { R 5' GGTACCGTGATGGTGATGGTGATGGGCATTGGCCATCGCCTCC } 3^{\prime}\end{array}$ & pDART \\
\hline plaS-1 & $\begin{array}{l}\text { F 5' CAAGACAATGTCTAGGCCATGGGAGGCGATGGCC 3' } \\
\text { R 5' ACATACTCATTCTAGCTCCTTGTCGTTACTGCTGTCCGTATTGCG 3' }\end{array}$ & pDART \\
\hline plaA-2 & $\begin{array}{l}\text { F 5' GCATGCCTAGCGACAAGGAGTCGGCATGA 3' } \\
\text { R } 5 \text { 'TCTAGATTAGTGATGGTGATGGTGATGGGCATTG GCCATCGCCTC 3' }\end{array}$ & pDSK519 \\
\hline plaS-2 & $\begin{array}{l}\text { F 5' TCTAGAGCCATGGGAGGCGATGGC 3' } \\
\text { R 5' AGCTCTTACTGCTGTCCGTATTGCG 3' }\end{array}$ & pDSK519 \\
\hline
\end{tabular}

$\mathrm{F}$ denotes forward primer. $\mathrm{R}$ denotes reverse primer.

\subsection{Analyses of PlaA Expression and Fermentation}

Recombinant cells were grown in the LB or M9 medium supplemented with $60 \mu \mathrm{g} / \mathrm{mL}$ kanamycin. When P. fluorescens ZYAI reached 0.8 absorbance (path length $1 \mathrm{~cm}$ ) at $600 \mathrm{~nm}\left(A_{600}\right), 1 \mathrm{mM}$ (final concentration) of isopropyl- $\beta$-D-thiogalactopyranoside (IPTG) was added to the culture in order to induce PlaA expression. To separate the supernatant and cell pellet, the culture broth was centrifuged at 18,000 $\mathrm{rcf}$ for $10 \mathrm{~min}$. The proteins of the cell pellet and the supernatant were analyzed using sodium dodecylsulfate-polyacrylamide gel electrophoresis (SDS-PAGE) in 10\% polyacrylamide gels, following Laemmli's method [25]. The proteins were transferred onto a nitrocellulose membrane (Amersham, UK) for western blotting, performed as previously described [25] using anti-His primary antibody (Qiagen, Germany) and anti-mouse IgG secondary antibody chemiluminescence system (Advansta, San Jose, CA, USA).

To examine the possibility of high-level secretion-based PlaA production by the fed-batch fermentation, recombinant $P$. fluorescens ZYAI harboring pABC/PlaA was cultivated in a $500 \mathrm{~mL}$ flask containing $200 \mathrm{~mL} \mathrm{LB}$ with $60 \mu \mathrm{g} / \mathrm{mL}$ kanamycin at $30{ }^{\circ} \mathrm{C}$ for $24 \mathrm{~h}$. The seed culture was inoculated in a $2 \mathrm{~L}$ M9 medium with $60 \mu \mathrm{g} / \mathrm{mL}$ kanamycin. Batch fermentation was performed at $30{ }^{\circ} \mathrm{C}$ in a $5 \mathrm{~L}$ jar fermenter (New Brunswick BioFlo 310, Eppendorf, Germany). After batch fermentation, IPTG was added at a final concentration of $1 \mathrm{mM}$, and $50 \%$ glycerol solution with $60 \mu \mathrm{g} / \mathrm{mL}$ kanamycin and trace metal solution was fed into the culture at a feeding rate of $5 \mathrm{~mL} / \mathrm{h}$. Fed-batch fermentation was performed at $25^{\circ} \mathrm{C}$. The $\mathrm{pH}$ was controlled at 7.4 by adding $15 \%$ aqueous ammonia, and the dissolved oxygen level was constantly adjusted to $30 \%$ by controlling the agitation speed, airflow, and supplemental pure oxygen flow during batch and fed-batch fermentation.

\subsection{Measurement of Secretory PlaA Activity}

PlaA activity was detected by directly cultivating cells on lecithin agar plates, which were prepared by adding 1.5\% phosphatidylcholine (Amresco, Solon, OH, USA), $0.5 \%$ taurocholic acid (Merck, Germany), $10 \mathrm{mM} \mathrm{CaCl}_{2}$, and antibiotics to autoclaved 1.5\% LB agar. After the colony was incubated at $25^{\circ} \mathrm{C}$ for four days, the phospholipase activity zone (Pz) was measured. As described by Price et al. [26,27], Pz was calculated by dividing colony diameter with the colony diameter plus opaque and transparent diameter around the colony. When $\mathrm{Pz}=1$, PlaA activity is considered negative and, as PlaA activity increases, Pz value approaches zero. We quantified PlaA activities on lecithin agar plates using the 1-Pz scoring system. Experiments were carried out on three separate occasions using a multi-gauge program. 
The relative activity of the secreted PlaA was measured using $\mathrm{N}-((6-(2,4-\mathrm{DNP})$ amino) hexanoyl) 1-(BODIPY FL C5)-2-hexyl-sn-glycero-3-phophoethanolamin (PED-A1) (Invitrogen, USA) as a fluorogenic phospholipase A1 substrate. The PED-A1 solution consists of $45 \mathrm{nM}$ PED-A1, $10 \mathrm{mM}$ Tris- $\mathrm{HCl}$ (pH 8.0), $100 \mathrm{mM} \mathrm{NaCl}$, and $10 \mathrm{mM} \mathrm{CaCl}_{2}$. A $90 \mu \mathrm{L}$ PED-A1 solution was incubated with $10 \mu \mathrm{L}$ supernatant of the culture medium in a 96-well microplate [28]. A Tecan-Genios-Pro multimode microplate reader was used to measure fluorescence intensity, and Magellan software was used to analyze the measurements. The fluorescence intensity was determined with an incident excitation light of wavelength of $485 \mathrm{~nm}$, and emission was detected at wavelength of $538 \mathrm{~nm}$. For the absolute estimation of PlaA activity in unit, the $\mathrm{pH}$-stat method was employed using an automatic $\mathrm{pH}$ titrator (Metrohm Tiamo, Switzerland). The lecithin substrate containing $20 \mathrm{mM}$ lecithin, $6.4 \mathrm{mM} \mathrm{CaCl}$, and $3.2 \mathrm{mM}$ sodium deoxycholate was homogenized for $10 \mathrm{~min}$. Then, the rate of reaction was monitored by titrating with $10 \mathrm{mM} \mathrm{NaOH}$ at $\mathrm{pH} 8.0$ and $40{ }^{\circ} \mathrm{C}$ for $3 \mathrm{~min}$ [29]. One unit (U) was defined as the release of $1 \mu \mathrm{M}$ of fatty acid per min under experimental conditions.

\subsection{Degumming of Crude Plant Oil and Lecithin Hydrolysis}

The fermentation broth containing the secreted PlaA was diafiltrated using a tangential flow filtration membrane with a molecular weight cut-off of $10 \mathrm{kDa}$ in $50 \mathrm{mM}$ Tris- $\mathrm{HCl}$ (pH 8.0). For the PlaA-catalyzed degumming process, the $5 \mathrm{~mL}$ of crude sesame oil was heated to $60^{\circ} \mathrm{C}$ in a water bath for $1 \mathrm{~h}$ and cooled down to $40^{\circ} \mathrm{C}$. The PlaA solution was added to crude sesame oil and vortexed for $1 \mathrm{~min}$. The degumming reaction was conducted by shaking at $300 \mathrm{rpm}$ and $40^{\circ} \mathrm{C}$ for $24 \mathrm{~h}$ as previously reported [12].

The substrate solution for lecithin hydrolysis consisted of $10 \%(w / v)$ lecithin, $600 \mathrm{mM}$ sodium chloride, $20 \mathrm{mM}$ calcium chloride, and $1 \mathrm{mM}$ sodium taurocholate. The substrate solution $\mathrm{pH}$ was adjusted to 8.0 using a $5 \mathrm{~N}$ sodium hydroxide solution. The hydrolysis reaction of lecithin was started by adding an appropriate amount of PlaA solution to $30 \mathrm{~mL}$ of the substrate solution and incubating at $40{ }^{\circ} \mathrm{C}$ while being stirred with a magnetic stirrer. After the reaction was terminated, the amount of lecithin converted to lysolecithin was measured by titrating the released fatty acids with a $0.1 \mathrm{~N} \mathrm{NaOH}$ solution to raise back to $\mathrm{pH} 8.0$.

\section{Results}

\subsection{PlaA Expression in E. coli}

Serratia species secrete PlaA naturally with the help of plaS, which is juxtaposed with plaA as an operon [2]. However, PlaA was localized inside E. coli cells despite being co-expressed with PlaS [2]. Furthermore, only a marginal amount of recombinant PlaA is obtained from liter-scale E. coli cultures due to substantial inhibition of cell growth and protein biosynthesis [12]. In this study, we intended to produce PlaA efficiently in a bacterial host by secreting the PlaA via the functionally reconstituted ABC transporter system, TliDEF, in a heterologous bacterial strain (Figure 1). We needed to understand how the two different functional elements, PlaS and the ABC transporter, interplay in protein secretion. For this purpose, various plasmids expressing PlaA attached to LARD3 and PlaS were constructed. 
(A)

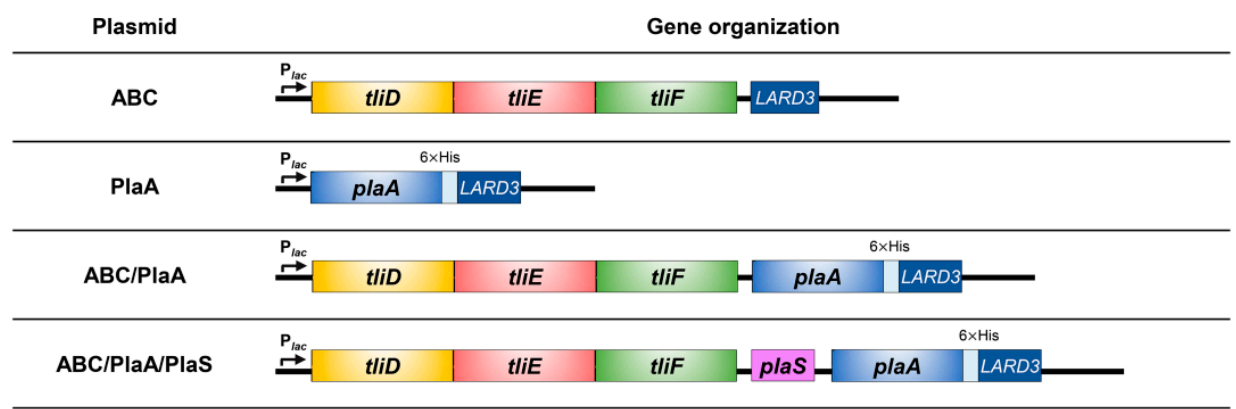

(B)

(C)

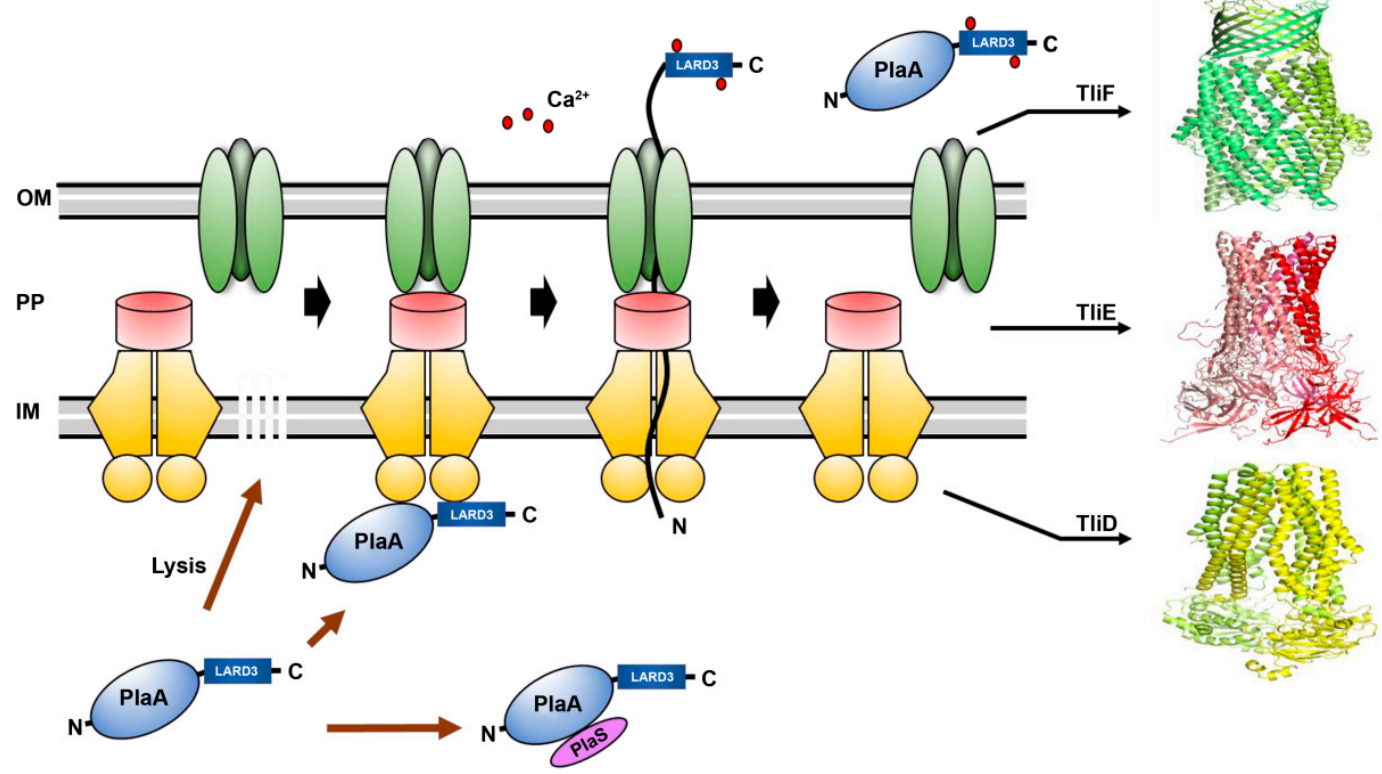

Figure 1. Construction of recombinant plasmids and the scheme of bacterial phospholipase A (PlaA) secretion by ABC transporter in P. fluorescens ZYAI. (A) Recombinant plasmids were constructed by incorporating plaA and plaS into pDART. All genes were under the control of the E. coli lac promoter. Each original ribosomal binding site is placed at the upstream positions of plaA and plaS. ABC: pDART; PlaA: pPlaA; ABC/PlaA: pDART-PlaA; ABC/PlaA/PlaS: pDART-PlaA/PlaS. (B) Schematic representation of PLA1 secretion by ABC transporter. The TliDEF are separated in the resting state. When the C-terminal of $\mathrm{ABC}$ transporter recognition domain 3 (LARD3) binds to TliD, the $\mathrm{ABC}$ transporter assembles. The PlaA is secreted into the extracellular medium through the ABC transporter. The extracellular calcium ions attach to certain parts of the signal sequence and pull the remaining protein out of the cell. If the PlaA is accumulated in the cell, it induces cell lysis. The PlaS reduces PlaA secretion with interaction of PlaA. (C) The three-dimenional (3D) structures of the TliDEF. The structures of dimeric TliD, hexameric TliE, and trimeric TliF were predicted by SWISS-MODEL. OM: outer membrane; PP: periplasm; IM: inner membrane.

All plasmids were constructed using pDSK519 [30], a broad host range vector, for expression in different hosts (Figure 1A). We first analyzed the constructed plasmids in E. coli to check if the plasmids were constructed properly. E. coli harboring different plasmids was inoculated using toothpicks onto lecithin plates and incubated (Figure 2A). PlaA activity can be detected on a lecithin plate by observing the conversion of lecithin into visually detectable substances, which form a double-layered halo around each colony [31]. Within each halo, an opaque halo, composed of glycerophosphocholin and fatty acid precipitation, was formed in the inner region (near the colony), with a transparent halo, consisting of water-soluble lysolecithin, in the outermost region. In our experiments, E. coli harboring plaA showed double-halos, which included both opaque and transparent halos. The halo size was increased further 
by supplementing the cells with plaS. The PlaA activity level was quantified by Pz value and activity of colonies harboring both plaA and plaS was the highest (Figure 2B). Interestingly, the colonies harboring plaA without plaS were somewhat translucent on the LB plate (Figure 2C), and they exhibited retarded cell growth (Figure 2D). We believe these symptoms indicate that the expression of PlaA without PlaS in E. coli is toxic to the host cell. The toxic effect was alleviated by co-expression of PlaS, making the colonies on the agar plate opaque again and rescuing the growth rate. Next, we scrutinized the liquid culture of $E$. coli supplemented with the genes for the $\mathrm{ABC}$ transporter, but there was no detectable amount of secreted PlaA in the culture supernatant of the cells harboring plaA alone or both plaA and plaS (Figure 2E). Perhaps, we could not detect PlaA in the liquid culture supernatant because of the suppressive regulation of gene expression in liquid culture, in contrast to agglomerated cell colonies on the solid agar plate. Serratia sp. MK1 was also tested for PlaA production with plasmids shown in Figure $1 \mathrm{~A}$, but there was no additional secretory PlaA production compared to the wild type strain. In any case, these results indicate that E. coli and Serratia sp. are not a viable expression host for PlaA expression. Therefore, we decided to test whether P. fluorescens could be a viable replacement.

(A)
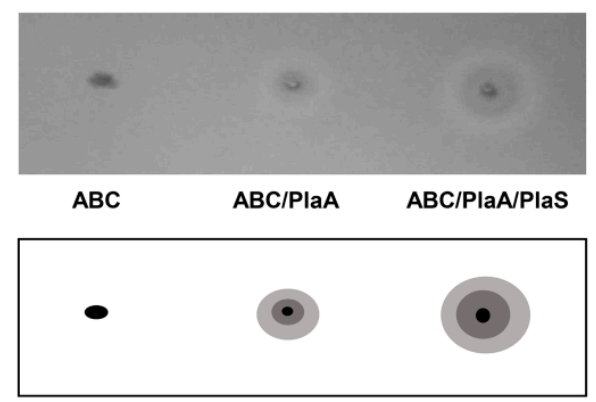

(B)

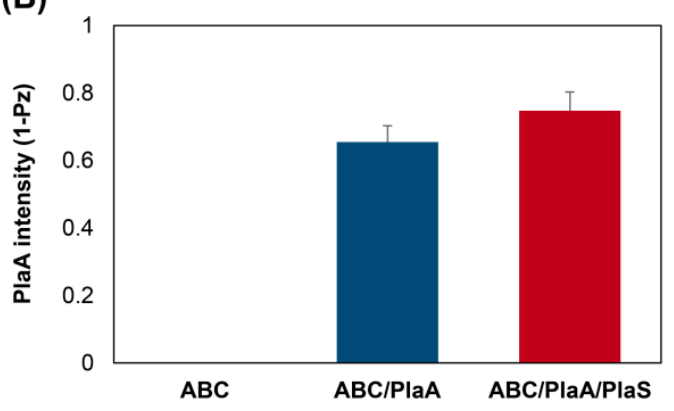

(C)

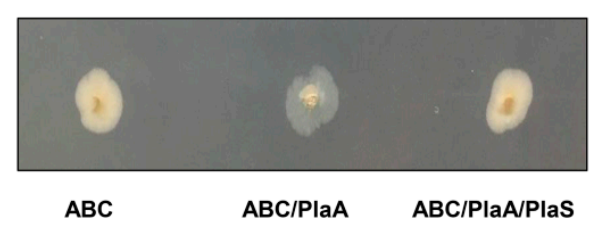

(D)

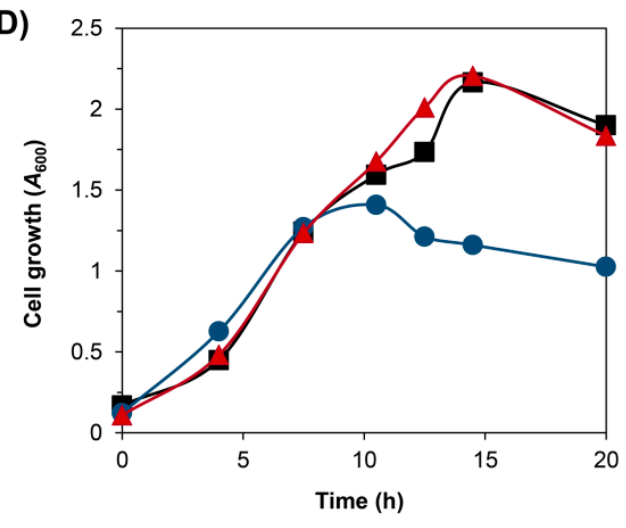

(E)

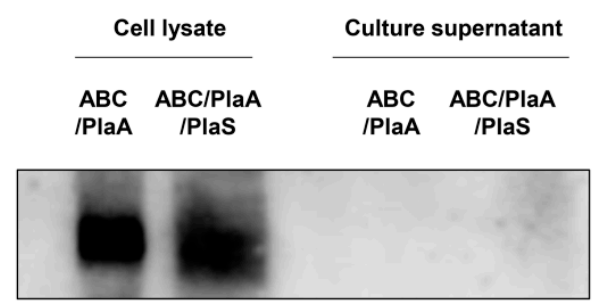

Figure 2. Phospholipase activity of recombinant PlaA in E. coli. (A) E. coli cells harboring each plasmid were grown on lecithin plates at $25{ }^{\circ} \mathrm{C}$ for two days. The schematic diagram illustrates zones of colony (black), an opaque halo formed by fatty acid precipitation (dark grey), and a transparent halo formed by water-soluble lysophospholipid (light grey). (B) PlaA activity was quantified by measuring halo zones around colonies on the lecithin plate. The Pz refers to colony diameter divided by colony diameter plus opaque and transparent zones diameter so $1-\mathrm{Pz}=0$ means no activity. (C) E. coli cells harboring each plasmid were grown on LB agar plate at $37^{\circ} \mathrm{C}$ for four days. (D) Growth curves of E. coli harboring different plasmids, $\mathrm{ABC}(\boldsymbol{\bullet}), \mathrm{ABC} / \mathrm{PlaA}(\bullet), \mathrm{ABC} / \mathrm{PlaA} / \mathrm{PlaS}(\boldsymbol{\Delta})$. The cells were cultured in the LB media with $1 \mathrm{mM}$ IPTG added at $A_{600}=0.8$. (E) Western blot analysis of PlaA from the samples of cell lysates and culture supernatants. The plasmids shown in Figure 1A were used for comparison. Error bars represent the standard deviation from three independent experiments. 


\subsection{Construction of P. fluorescens ZYAI}

We hypothesized that $P$. fluorescens could be an appropriate host for plaA expression since $p l a A$ is closely related to Serratia sp. MK1, the origin of plaA, and both of them are categorized in the same class of $\gamma$-proteobacteria. Furthermore, it is the natural host of the $\mathrm{ABC}$ transporter we are using and is proven capable of secreting many different types of recombinant proteins using the $\mathrm{ABC}$ transporter. The constructed plasmids (Figure 1A) were transformed into P. fluorescens $\Delta$ tiA $\Delta p r t A$ (hereafter $\Delta t p$ ) via electroporation. P. fluorescens $\Delta t p$, a knockout mutant of $P$. fluorescens SIK-W1 with tliA (lipase) and $\operatorname{prt} A$ (protease) genes knocked out, exhibits a superior level of detectable recombinant proteins in an extracellular medium when used as an expression host [19]. Although we were able to isolate E. coli colonies expressing PlaA, we failed to isolate $P$. fluorescens $\Delta t p$ transformed with pABC/PlaA which expresses plaA without plaS, as these cells did not make any colony. This is because E. coli has an expression control mechanism and P. fluorescens does not. On the agar plate, where no inducing agent is present, E. coli can grow as it expresses the LacI repressor from its genomic lacI gene, and this represses the lac promoter of our plasmid, enabling colony growth. It seems that uncontrolled PlaA expression without PlaS is too toxic for the cells to produce colonies. On the other hand, P. fluorescens $\Delta t p$ transformed with $\mathrm{pABC} / \mathrm{PlaA} / \mathrm{PlaS}$ made a few colonies because PlaS allowed P. fluorescens growth by mitigating PlaA toxicity in the cell. For controllable PlaA expression, we constructed a new knock-in mutant of $P$. fluorescens $\Delta t p$ using the E. coli lac operon system.

The entire lac operon from E. coli, including the lacI gene, was inserted into the chromosome of P. fluorescens $\Delta t p$. The lac operon (lacZ, lacY, lacA, and lacI) was inserted into the first gene algD of the alg operon to form the knock-in mutant P. fluorescens ZYAI (Supplementary Figure S1A). The alg operon [32,33] was selected as the knock-in insertion site because biosynthesized alginate, the metabolic product of alg operon genes, is assembled as a biofilm matrix in vivo [34,35] and is not beneficial for the suspension culture in liquid media.

The lac operon knocked-in P. fluorescens ZYAI could feed on lactose as its sole carbon source, and it made blue colonies using IPTG and X-gal, while P. fluorescens $\Delta t p$ and another mutant $P$. fluorescens algD::lacI cannot digest lactose (Supplementary Figure S1B). P. fluorescens algD::lacI was not induced by IPTG for gene expression under the lac promoter (Supplementary Figure S1C). This was caused by a lack of lacY and lacZ, which transport lactose and convert it to allolactose, the natural inducer [36]. The PlaS was essential when toxic PlaA was expressed in P. fluorescens $\Delta t p$; however, PlaA could be expressed without PlaS in P. fluorescens ZYAI. All of the P. fluorescens ZYAI colonies harboring plaA were opaque and grew well, unlike the E. coli colonies on LB plate as shown in Figure 2C,D, indicating that PlaA's cytotoxic activity was downregulated by the repression control of the gene expression in P. fluorescens ZYAI. To determine the optimum IPTG dose, the PlaA expression level was examined at different IPTG concentrations and analyzed via western blot. At $1 \mathrm{mM}$ IPTG, the highest PlaA secretion was observed. We also used M9 medium for the following experiments, not only because the PlaA expression level was higher in the M9 medium than in the LB (Supplementary Figure S1D), but also because PlaA takes up the majority of the M9 culture supernatant proteins with significantly fewer contaminant proteins.

\subsection{Secretion of PlaA in P. fluorescens ZYAI}

We examined the secretory production of PlaA in P. fluorescens ZYAI by introducing the plasmids described in Figure 1A. P. fluorescens ZYAI harboring pABC/PlaA formed colonies and showed an activity halo, including both the opaque and the transparent halos, while the colony harboring pABC/PlaA/PlaS showed a smaller activity halo (Figure 3A,B). To analyze PlaA secretion, P. fluorescens ZYAI harboring pABC/PlaA were cultured in M9 medium with IPTG induction, and the secretion was compared with $P$. fluorescens ZYAI harboring pABC/PlaA/PlaS (Figure 3C). Much more PlaA was secreted by the ABC transporter when plaA was expressed without plaS, while only a trace activity was measured in cells containing both plaA and plaS (Figure 3D). Moreover, P. fluorescens ZYAI expressing plaA secreted three times more PlaA than the noninducible P. fluorescens $\Delta t p$ supplemented with both 
plaA and plas (Figure 3E). P. fluorescens ZYAI harboring pABC/PlaA/PlaS showed the lowest PlaA activity in the culture supernatant. The induction-controlled PlaA expression in P. fluorescens ZYAI exhibited much better protein secretion than P. fluorescens $\Delta t p$ with co-expressed plaS.

(A)

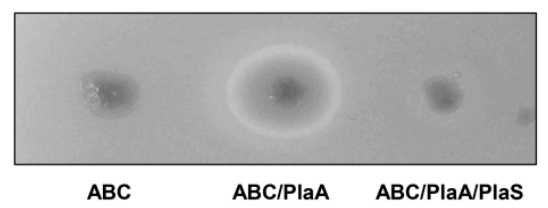

(B)

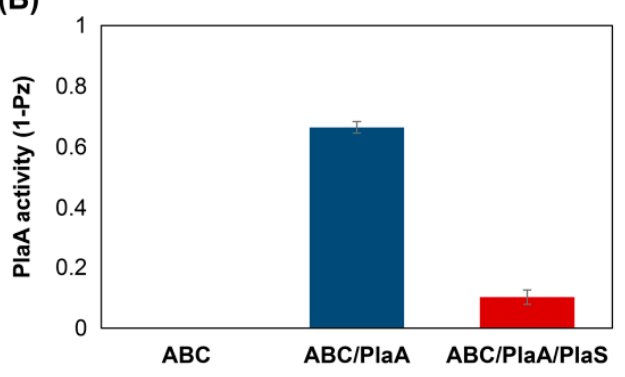

(C)

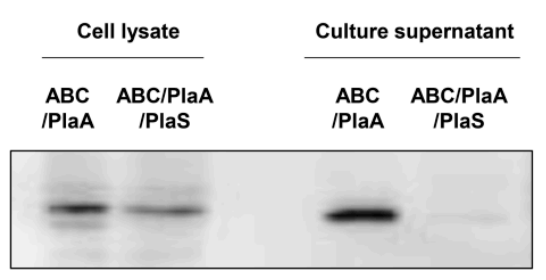

(D)

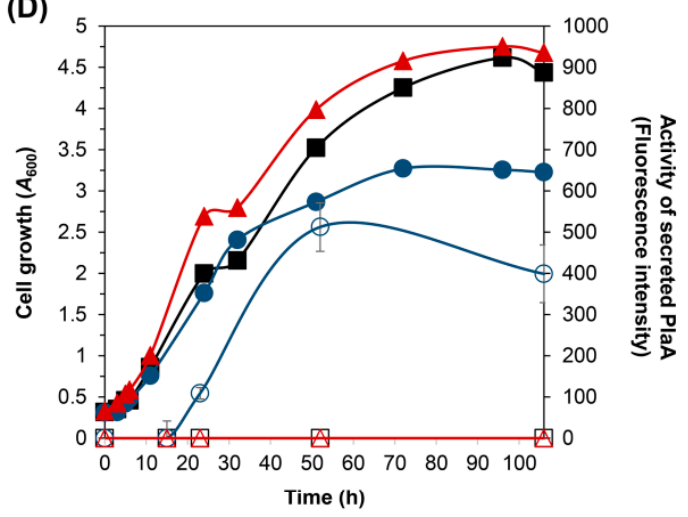

(E)

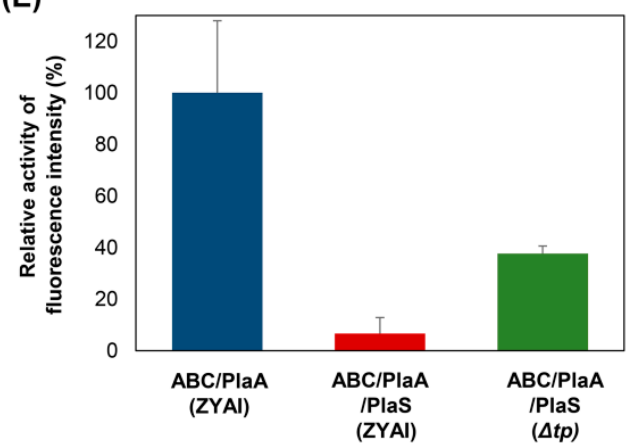

Figure 3. PlaA secretion by the $\mathrm{ABC}$ transporter system in P. fluorescens. (A) Each cell was grown on the lecithin plate at $25^{\circ} \mathrm{C}$ for four days. (B) PlaA activity was quantified by measuring the diameter of the halo zones around colonies on the lecithin plate. (C) Western blot analysis of PlaA from the samples of cell lysates and culture supernatants. The cells were cultured in M9 medium for four days with $1 \mathrm{mM}$ Isopropyl $\beta$-D-1-thiogalactopyranoside (IPTG) added at $A_{600}=0.8$. (D) Growth curves of $P$. fluorescens ZYAI harboring different plasmids and activity of secreted PlaA, ABC ( $\bullet$ and $\square), \mathrm{ABC} / \mathrm{PlaA}(\bullet$ and $\bigcirc$ ), $\mathrm{ABC} / \mathrm{PlaA} / \mathrm{PlaS}\left(\boldsymbol{\Delta}\right.$ and $\triangle$ ). The cells were cultured in M9 media with $1 \mathrm{mM}$ IPTG added at $A_{600}=0.8$. The PlaA activity was measured using PED-A1, fluorogenic substrate specific for PlaA in the culture supernatant. (E) The relative activity of $\mathrm{PlaA}, \mathrm{ABC} / \mathrm{PlaA}$, and $\mathrm{ABC} / \mathrm{PlaA} / \mathrm{PlaS}$ was measured using the fluorescence substrate PED-A1 with the activity of ABC/PlaA set at $100 \%$. The plasmids shown in Figure 1 were used for the experiments. All experiments were performed with $P$. fluorescens ZYAI except $\mathrm{ABC} / \mathrm{PlaA} / \mathrm{PlaS}$, the activity of which was compared in both P. fluorescens $\Delta t p$ and $P$. fluorescens ZYAI. Error bars represent the standard deviation from three independent experiments.

It was evident that the $\mathrm{ABC}$ transporter-mediated secretion of PlaA is crucial to the high-level secretion of PlaA in the inducible P. fluorescens ZYAI. As a control experiment, the ABC transporter's role in PlaA production was tested by checking the level of culture supernatant without the $\mathrm{ABC}$ transporter or LARD3, the C-terminal signal sequence. Without the $\mathrm{ABC}$ transporter in the plasmid, PlaA was only minimally localized to the extracellular medium, perhaps by the ABC transporter expressed from the single copy of the genomic $t l i D E F$ gene, which is not overexpressed (Supplementary Figure S2A). The wild-type PlaA, which lacks the LARD3 signal sequence, was also tested in P. fluorescens, but PlaA lacking LARD3 was not localized to the culture supernatant (Supplementary Figure S2B). These results confirmed that PlaA was secreted only by the conjugated LARD3 and the supplemented ABC transporter in P. fluorescens. 


\subsection{Production of PlaA in Fermenter}

In order to achieve high-level, medium-scale secretion-based PlaA production, an induced PlaA expression in P. fluorescens ZYAI containing pABC/PlaA was carried out in a fermenter using a two-phase protocol consisting of an M9-glycerol batch at $30{ }^{\circ} \mathrm{C}$ and glycerol fed-batch at $25^{\circ} \mathrm{C}$ (Figure 4). To proceed to the protein production phase after the $45 \mathrm{~h}$ batch culture, $1 \mathrm{mM}$ IPTG (final concentration) was added to induce the PlaA production. Even though the cell biomass was in a stationary state at $A_{600}$ around 16 while the culture was being fed constantly with the supplemental glycerol solution, the PlaA activity in the culture supernatant significantly increased up to $25 \mathrm{units} / \mathrm{mL}$ during $51 \mathrm{~h}$ glycerol fed-batch phase (Figure $4 \mathrm{~A}$ ). We also confirmed that the presence of $45.7 \mathrm{kDa} \mathrm{PlaA}$ in the culture supernatant via western blot (Figure 4B). The PlaA activity of the fed-batched culture supernatant at $96 \mathrm{~h}$ was estimated by $\mathrm{pH}$-stat assay, and the result showed that it was approximately 50-fold higher than that of the $5 \mathrm{~mL}$ test tube culture supernatant (Figure $4 \mathrm{C}$ ). The secreted PlaA concentration, estimated from the band density of SDS-PAGE and the western blot, was $17 \mathrm{mg} / \mathrm{L}$. The specific activity of PlaA measured by $\mathrm{pH}$-stat was $1433 \pm 139 \mathrm{U} / \mathrm{mg}$, and the calculated turnover number $\left(\mathrm{k}_{\text {cat }}\right)$ was $1091 \mathrm{~s}^{-1}$.

(A)

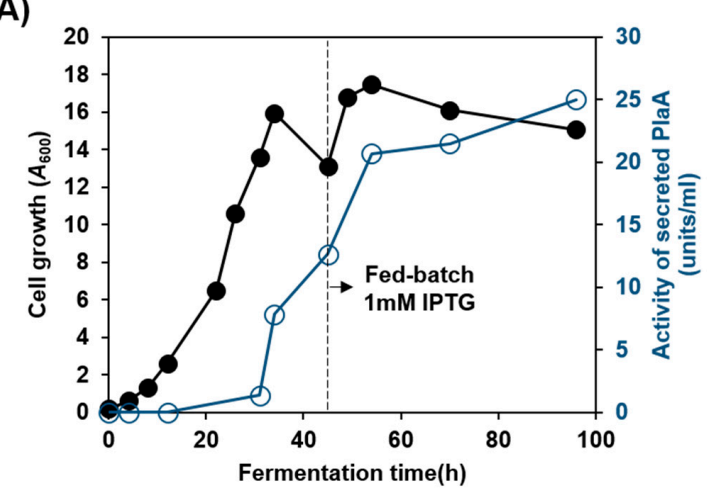

(B)

(h) $\quad \begin{array}{llllllllllll}4 & 8 & 12 & 22 & 26 & 31 & 34 & 45 & 49 & 54 & 70 & 96\end{array}$

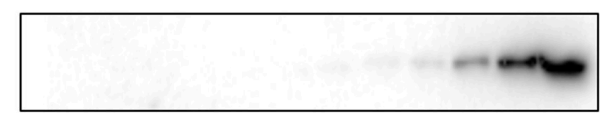

(C)

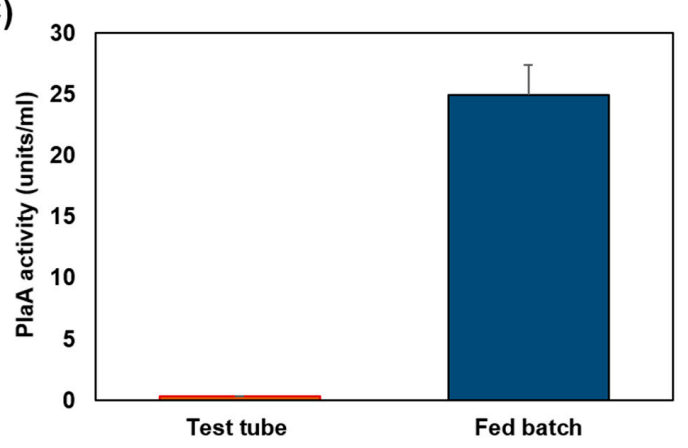

Figure 4. Fed-batch fermentation of $P$. fluorescens ZYAI harboring ABC/PlaA. The secretory production of PlaA by P. fluorescens ZYAI harboring ABC/PlaA was monitored with the samples collected from the fed-batch fermentation broth at different times. (A) Cell growth $(\bullet)$ was determined by measuring the optical density at a wavelength of $600 \mathrm{~nm}$ and the activity of secreted PlaA $(\bigcirc)$ was measured by pH-stat. (B) Western blot analysis was carried out with the culture supernatant using anti-His-tag. (C) The PlaA activity of $5 \mathrm{~mL}$ M9 medium and fed-batch fermentation in a $5 \mathrm{~L}$ fermenter was measured by $\mathrm{pH}$-stat. Error bars represent the standard deviation from three independent experiments. 


\subsection{Use of Secreted PlaA in Degumming Crude Plant Oil and Hydrolysis of Lecithin}

The PlaA solution prepared from the fermentation was used for degumming crude sesame oil and hydrolysis of crude lecithin to test its suitability in bio-catalytic applications. First, crude sesame oil was incubated with $10 \mu \mathrm{g}$ PlaA solution for $24 \mathrm{~h}$ at $40{ }^{\circ} \mathrm{C}$ to facilitate enzymatic degumming by PlaA. As shown in Figure 5A, cloudy crude oil was cleared as PlaA converted phospholipids to lysophospholipids. Next, we examined the hydrolysis of crude lecithin with PlaA. The increase of fatty acids released by the action of PlaA was directly proportional to the amount of enzyme used (Figure 5B), indicating that the recombinant PlaA successfully catalyzed lecithin hydrolysis. Time-course analysis showed that lecithin hydrolysis in 10\% aqueous lecithin solution eventually reached a plateau after $4 \mathrm{~h}$ of reaction under the presence of the secreted PlaA solution (Figure 5C). At the plateau, there was about $630 \mu$ mole of lysolecithin, which corresponded to a conversion of $27.0 \%$ of the total lecithin. These results suggest that the PlaA prepared via the ABC transporter-mediated secretion in P. fluorescens could be a promising industrial solution to produce lysolecithin or degum crude renewable oils.

(A)

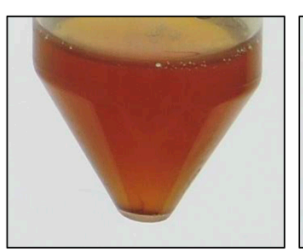

Crude oil

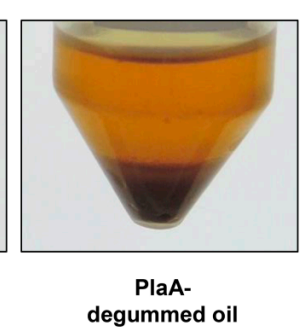

degummed oil

(B)

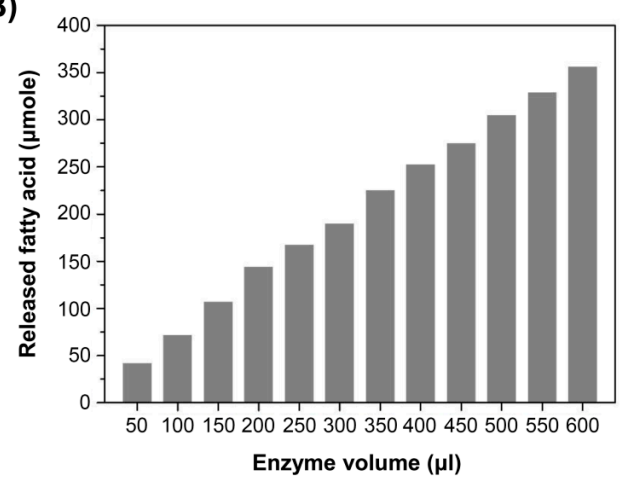

(C)

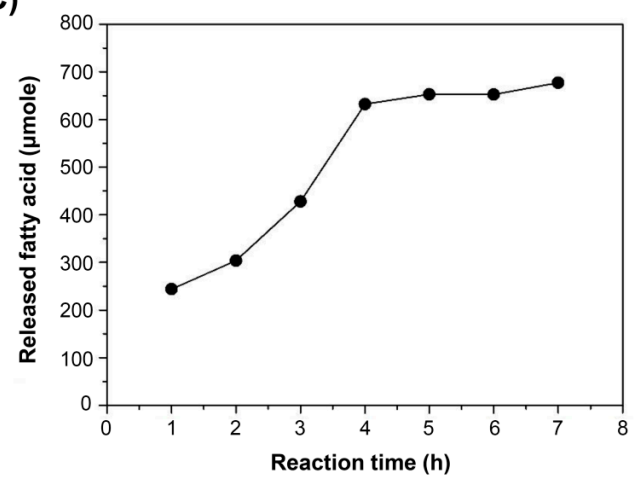

Figure 5. Degumming crude oil and lecithin hydrolysis using the culture supernatant of PlaA. (A) The crude sesame oil was incubated with $10 \mu \mathrm{g} \mathrm{PlaA}$ solution for $24 \mathrm{~h}$ at $40^{\circ} \mathrm{C}$. (B) Different amounts of PlaA solution were added to the substrate solution. After $2 \mathrm{~h}$ of incubation at $40^{\circ} \mathrm{C}$, the conversion of lecithin to lysolecithin was measured. (C) The conversion of lecithin to lysolecithin by the secreted PlaA was measured at various reaction times. 


\section{Discussion and Conclusions}

In this report, we propose that $\mathrm{ABC}$-transporter-based PlaA production can be a favorable alternative to the conventional cytoplasmic expression in bacteria. Since PLA1 is bacteriotoxic when accumulated in the cytoplasm, the mass production of foreign PLA1 with conventional methods was hampered by low cell growth and consequent global suppressive regulation of gene expression [12]. Previously, plaA, a bacterial PLA1 from Serratia sp. MK1 [2] and its engineered variants $[37,38]$ have been expressed mainly in E. coli. Due to PlaA's toxicity to cellular membranes, an effort to develop an efficient bacterial expression system has not been effective for bacterial PlaA production. We also attempted to express recombinant PlaA in E. coli or Serratia sp. MK1, but as the expressed PlaA accumulated in the cytoplasm, the bacteriotoxic activity of PlaA retarded cell growth (Figure 2C,D). When P. fluorescens strain equipped with an $\mathrm{ABC}$ protein exporter was used, the PlaA molecules that were initially synthesized in the cytoplasm could be translocated swiftly to the extracellular medium, where they can no longer exert any serious influence on cell viability (Figure 1B). We demonstrated that the ABC protein exporter-mediated secretion-based production in P. fluorescens can be a versatile tool for producing bacteriotoxic proteins that would be difficult to express otherwise.

Gram-negative bacteria contain various secretion systems, ranging from the type I secretion system (T1SS) to the type VI secretion system (T6SS) [39]. The PlaA used in this study is originally secreted by the type III secretion system (T3SS), similar to S. marcescens PhlA [40] and Yersinia YplA [41]. These PLA1s are secreted through the flagella-related T3SS, which usually mediates the bacterial flagellar formation in E. coli and Serratia species [40,42-46]. PlaA, PhlA, and YplA have an N-terminal signal peptide that is about 19-23 residues of hydrophobic amino acids [47] and have been predicted to be secreted by the T3SS [48]. In our preliminary experiments, we tested PlaA secretion by native T3SS of $P$. fluorescens by transforming it with plasmids harboring unmodified versions (without LARD3 signal sequence) of plaA or plaA/plaS (Supplementary Figure S2B). The PlaA was not detected in the liquid culture supernatant even though PlaA activity was observable on the agar plate activity assay. The regulators and controllers of $P$. fluorescens T3SS did not seem to operate properly for the Serratia PlaA in liquid culture, perhaps because Serratia PlaA expression is delicately controlled by a flagellar regulator $[5,43,49]$ or cysteine biosynthesis of Serratia [50]. However, PlaA could be secreted by C-terminal LARD3 signal sequence via P. fluorescens ABC transporter (T1SS) even though it is incompatible with $P$. fluorescens T3SS.

The plaA is a toxic gene which can deteriorate membrane integrity by hydrolyzing phospholipids. The associated protein PlaS specializes in modulating or regulating PlaA activity. PlaS inhibits PlaA by interacting directly with PlaA, and it facilitates the protection of the cell interior $[5,43,44,47]$. Our results were consistent with this. In E. coli, PlaS restored normal colony physiology and cell growth rate (Figure 2C,D). It was similar in P. fluorescens $\Delta t p$, which requires strict PlaS co-expression to survive on expressing PlaA. However, the PlaS was not necessary in the lacI-controlled P. fluorescens ZYAI strain. Furthermore, PlaS reduced the ABC transporter-mediated secretion of PlaA (Figure 3B). It seems that the intracellular interaction of PlaA and PlaS could interfere with the PlaA unfolding process, which happens during the T1SS-dependent secretion, resulting in a decreased secretion level (Figure 1B). It is noteworthy that heterodimer formation decreases the protein secretion across the membrane in many transport mechanisms [51,52]. Therefore, it is expected that the binding and subsequent heterodimer formation stabilizes the folded structure of the cargo proteins, resulting in a decreased secretion. The newly developed lacI-regulated P. fluorescens ZYAI can be used as an alternative to PlaS co-expression, where we can control the PlaA expression, constraining the damage to cell viability done by PlaA's bacteriotoxic activity. The newly developed strain P. fluorescens ZYAI enabled us to use a convenient, controlled, and inducible expression of recombinant genes, permitting us to overproduce bacteriotoxic proteins such as PlaA.

In conclusion, we showed that bacteriotoxic PlaA can be produced and secreted using an ABC transporter in a bacterial host. The secreted enzyme can be put to use readily for degumming processes, such as the enzymatic conversion of lecithin to lysolecithin. The toxic protein PlaA, which previously 
proved difficult to express in bacterial cells, was produced successfully by fed-batch fermentation of the newly developed knock-in mutant strain P. fluorescens ZYAI, which has lac operon for controllable expression. The regulation of gene expression by lacI enabled reliable PlaA gene expression and allowed sustained PlaA production in the extracellular medium. The ABC transporter-mediated secretion in P. fluorescens ZYAI could be a promising alternative to the conventional intracellular protein production methods for the production of bacteriotoxic proteins such as PlaA.

Supplementary Materials: The following are available online at http://www.mdpi.com/2076-2607/8/2/239/s1, Figure S1: Construction of $P$. fluorescens ZYAI, Figure S2: Secretion of PlaA by the ABC transporter system.

Author Contributions: Conceptualization, J.H.A.; methodology, J.Y.P. and J.Y.O.; validation, J.Y.P. and J.Y.O.; investigation, J.Y.P., J.Y.O., and J.H.P.; writing-original draft preparation, J.P., J.Y.P., G.T.E., and J.Y.O.; writing-review and editing, J.H.A., J.K.S., and S.C.K.; supervision, J.H.A.; project administration, J.H.A. All authors have read and agreed to the published version of the manuscript.

Funding: This work was supported by the Intelligent Synthetic Biology Center of Global Frontier Project funded by the Ministry of Science and ICT (2011-0031955), the Korea Research Institute of Chemical Technology under grant number KK1704-A00, SS2042-10, the R\&D programs of MOTIE/KEIT under grant 10077291, 10080592 and the Korea Science Academy of KAIST with funds from the Ministry of Science and ICT.

Acknowledgments: We are grateful to Hyunjong Byun for critical review and suggestion for manuscript readability.

Conflicts of Interest: The authors declare that they have no competing interests.

\section{References}

1. Richmond, G.S.; Smith, T.K. Phospholipases A(1). Int. J. Mol. Sci. 2011, 12, 588-612. [CrossRef] [PubMed]

2. Song, J.K.; Kim, M.K.; Rhee, J.S. Cloning and expression of the gene encoding phospholipase A1 from Serratia sp. MK1 in Escherichia coli. J. Biotechnol. 1999, 72, 103-114. [CrossRef]

3. Shiba, Y.; Ono, C.; Fukui, F.; Watanabe, I.; Serizawa, N.; Gomi, K.; Yoshikawa, H. High-Level Secretory Production of Phospholipase A1 by Saccharomyces cerevisiae and Aspergillus oryzae. Biosci. Biotechnol. Biochem. 2001, 65, 94-101. [CrossRef] [PubMed]

4. Dekker, N.; Tommassen, J.; Lustig, A.; Rosenbusch, J.P.; Verheij, H.M. Dimerization regulates the enzymatic activity of Escherichia coli outer membrane phospholipase A. J. Biol. Chem. 1997, 272, 3179-3184. [CrossRef]

5. Givskov, M.; Molin, S. Secretion of Serratia liquefaciens phospholipase from Escherichia coli. Mol. Microbiol. 1993, 8, 229-242. [CrossRef]

6. Yang, B.; Wang, Y.-H.; Yang, J.-G. Optimization of enzymatic degumming process for rapeseed oil. J. Am. Oil Chem. Soc. 2006, 83, 653-658. [CrossRef]

7. Yang, B.; Zhou, R.; Yang, J.-G.; Wang, Y.-H.; Wang, W.-F. Insight into the enzymatic degumming process of soybean oil. J. Am. Oil Chem. Soc. 2008, 85, 421-425. [CrossRef]

8. Bang, H.J.; Kim, I.H.; Kim, B.H. Phospholipase A1-catalyzed hydrolysis of soy phosphatidylcholine to prepare 1-alpha-glycerylphosphorylcholine in organic-aqueous media. Food Chem. 2016, 190, 201-206. [CrossRef]

9. Yang, J.-G.; Wang, Y.-H.; Yang, B.; Mainda, G.; Guo, Y. Degumming of vegetable oil by a new microbial lipase. Food Technol. Biotechnol. 2006, 44, 101.

10. Sheelu, G.; Kavitha, G.; Fadnavis, N.W. Efficient immobilization of lecitase in gelatin hydrogel and degumming of rice bran oil using a spinning basket reactor. J. Am. Oil Chem. Soc. 2008, 85, 739-748. [CrossRef]

11. Songer, J.G. Bacterial phospholipases and their role in virulence. Trends Microbiol. 1997, 5, 156-161. [CrossRef]

12. Lim, H.J.; Park, Y.J.; Jang, Y.J.; Choi, J.E.; Oh, J.Y.; Park, J.H.; Song, J.K.; Kim, D.M. Cell-free synthesis of functional phospholipase A1 from Serratia sp. Biotechnol. Biofuels 2016, 9, 159. [CrossRef] [PubMed]

13. Landry, T.D.; Chew, L.; Davis, J.W.; Frawley, N.; Foley, H.H.; Stelman, S.J; Thomas, J.; Wolt, J.; Hanselman, D.S. Safety evaluation of an alpha-amylase enzyme preparation derived from the archaeal order Thermococcales as expressed in Pseudomonas fluorescens biovar I. Regul. Toxicol. Pharmacol. 2003, 37, 149-168. [CrossRef]

14. Rainey, P.B.; Bailey, M.J. Physical and genetic map of the Pseudomonas fluorescens SBW25 chromosome. Mol. Microbiol. 1996, 19, 521-533. [CrossRef] [PubMed]

15. Schneider, J.C.; Jenings, A.F.; Mun, D.M.; McGovern, P.M.; Chew, L.C. Auxotrophic markers pyrF and proC can replace antibiotic markers on protein production plasmids in high-cell-density Pseudomonas fluorescens fermentation. Biotechnol. Prog. 2005, 21, 343-348. [CrossRef] [PubMed] 
16. Squires, C.H.; Retallack, D.M.; Chew, L.C.; Ramseier, T.M.; Schneider, J.C.; Talbot, H.W. Heterologous protein production in P. fluorescens. BioProcesss Int. 2004, 2, e58.

17. Ryu, J.; Lee, U.; Park, J.; Yoo, D.H.; Ahn, J.H. A vector system for ABC transporter-mediated secretion and purification of recombinant proteins in Pseudomonas species. Appl. Environ. Microbiol. 2015, 81, 1744-1753. [CrossRef]

18. Ahn, J.H.; Pan, J.G.; Rhee, J.S. Identification of the tliDEF ABC transporter specific for lipase in Pseudomonas fluorescens SIK W1. J. Bacteriol. 1999, 181, 1847-1852. [CrossRef]

19. Son, M.; Moon, Y.; Oh, M.J.; Han, S.B.; Park, K.H.; Kim, J.G.; Ahn, J.H. Lipase and protease double-deletion mutant of Pseudomonas fluorescens suitable for extracellular protein production. Appl. Environ. Microbiol. 2012, 78, 8454-8462. [CrossRef]

20. Kim, M.K.; Kim, J.K.; Rhee, J.S. Isolation of a phospholipase A1-producing microorganism. J. Ind. Microbiol. 1996, 16, 171-174. [CrossRef]

21. Sambrook, J.; Russell, D. Molecular Cloning: A Laboratory Manual; Cold Spring Harbor Laboratory Press: New York, NY, USA, 2001.

22. Ahn, J.H.; Pan, J.G.; Rhee, J.S. Homologous expression of the lipase and ABC transporter gene cluster, tliDEFA, enhances lipase secretion in Pseudomonas spp. Appl. Environ. Microbiol. 2001, 67, 5506-5511. [CrossRef] [PubMed]

23. de Marco, A.; Deuerling, E.; Mogk, A.; Tomoyasu, T.; Bukau, B. Chaperone-based procedure to increase yields of soluble recombinant proteins produced in E. coli. BMC Biotechnol. 2007, 7, 32. [CrossRef] [PubMed]

24. Schafer, A.; Tauch, A.; Jager, W.; Kalinowski, J.; Thierbach, G.; Puhler, A. Small mobilizable multi-purpose cloning vectors derived from the Escherichia coli plasmids pK18 and pK19: selection of defined deletions in the chromosome of Corynebacterium glutamicum. Gene 1994, 145, 69-73. [CrossRef]

25. Chung, C.W.; You, J.; Kim, K.; Moon, Y.; Kim, H.; Ahn, J.H. Export of recombinant proteins in Escherichia coli using $\mathrm{ABC}$ transporter with an attached lipase $\mathrm{ABC}$ transporter recognition domain (LARD). Microb. Cell Fact. 2009, 8, 11. [CrossRef] [PubMed]

26. Kothavade, R.J.; Panthaki, M.H. Evaluation of phospholipase activity of Candida albicans and its correlation with pathogenicity in mice. J. Med. Microbiol. 1998, 47, 99-102. [CrossRef] [PubMed]

27. Price, M.F.; Wilkinson, I.D.; Gentry, L.O. Plate method for detection of phospholipase activity in Candida albicans. Sabouraudia J. Med. Vet. Mycol. 1982, 20, 7-14. [CrossRef]

28. Vassar, R.J.; Potel, M.J.; Josephs, R. Studies of the fiber to crystal transition of sickle cell hemoglobin in acidic polyethylene glycol. J. Mol. Biol. 1982, 157, 395-412. [CrossRef]

29. Reynolds, L.J.; Washburn, W.N.; Deems, R.A.; Dennis, E.A. Assay strategies and methods for phospholipases. Methods Enzymol. 1991, 197, 3-23.

30. Keen, N.T.; Tamaki, S.; Kobayashi, D.; Trollinger, D. Improved broad-host-range plasmids for DNA cloning in gram-negative bacteria. Gene 1988, 70, 191-197. [CrossRef]

31. Chrisope, G.L.; Fox, C.W.; Marshall, R.T. Lecithin agar for detection of microbial phospholipases. Appl. Environ. Microbiol. 1976, 31, 784-786. [CrossRef]

32. Gimmestad, M.; Sletta, H.; Ertesvag, H.; Bakkevig, K.; Jain, S.; Suh, S.J.; Skjak-Braek, G.; Ellingsen, T.E.; Ohman, D.E.; Valla, S. The Pseudomonas fluorescens AlgG protein, but not its mannuronan C-5-epimerase activity, is needed for alginate polymer formation. J. Bacteriol. 2003, 185, 3515-3523. [CrossRef]

33. Wozniak, D.J.; Wyckoff, T.J.; Starkey, M.; Keyser, R.; Azadi, P.; O’Toole, G.A.; Parsek, M.R. Alginate is not a significant component of the extracellular polysaccharide matrix of PA14 and PAO1 Pseudomonas aeruginosa biofilms. Proc. Natl. Acad. Sci. USA 2003, 100, 7907-7912. [CrossRef] [PubMed]

34. Mann, E.E.; Wozniak, D.J. Pseudomonas biofilm matrix composition and niche biology. FEMS Microbiol. Rev. 2012, 36, 893-916. [CrossRef] [PubMed]

35. Rehm, B.H. Bacterial polymers: biosynthesis, modifications and applications. Nat. Rev. Microbiol. 2010, 8 , 578-592. [CrossRef]

36. Studier, F.W. Protein production by auto-induction in high-density shaking cultures. Protein Expr. Purif. 2005, 41, 207-234. [CrossRef] [PubMed]

37. Song, J.K.; Rhee, J.S. Simultaneous enhancement of thermostability and catalytic activity of phospholipase A(1) by evolutionary molecular engineering. Appl. Environ. Microbiol. 2000, 66, 890-894. [CrossRef]

38. Song, J.K.; Rhee, J.S. Enhancement of stability and activity of phospholipase A(1) in organic solvents by directed evolution. Biochim. Biophys. Acta 2001, 1547, 370-378. [CrossRef] 
39. Costa, T.R.; Felisberto-Rodrigues, C.; Meir, A.; Prevost, M.S.; Redzej, A.; Trokter, M.; Waksman, G. Secretion systems in Gram-negative bacteria: structural and mechanistic insights. Nat. Rev. Microbiol. 2015, 13, 343-359. [CrossRef]

40. Castelli, M.E.; Véscovi, E.G. The Rcs signal transduction pathway is triggered by enterobacterial common antigen structure alterations in Serratia marcescens. J. Bacteriol. 2011, 193, 63-74. [CrossRef]

41. Zhou, X.; Nydam, S.D.; Christensen, J.E.; Konkel, M.E.; Orfe, L.; Friel, P.; Call, D.R. Identification of potential type III secretion proteins via heterologous expression of Vibrio parahaemolyticus DNA. Appl. Environ. Microbiol. 2012, 78, 3492-3494. [CrossRef]

42. Young, B.M.; Young, G.M. YplA is exported by the Ysc, Ysa, and flagellar type III secretion systems of Yersinia enterocolitica. J. Bacteriol. 2002, 184, 1324-1334. [CrossRef] [PubMed]

43. Givskov, M.; Eberl, L.; Christiansen, G.; Benedik, M.J.; Molin, S. Induction of phospholipase- and flagellar synthesis in Serratia liquefaciens is controlled by expression of the flagellar master operon flhD. Mol. Microbiol. 1995, 15, 445-454. [CrossRef] [PubMed]

44. Meysick, K.C.; Seidman, J.; Falconio, J.R. The Yersinia pseudotuberculosis YplA phospholipase differs in its activity, regulation and secretion from that of the Yersinia enterocolitica YplA. Microb. Pathog. 2009, 47, $24-32$. [CrossRef] [PubMed]

45. Schmiel, D.H.; Young, G.M.; Miller, V.L. The Yersinia enterocolitica Phospholipase Gene yplA Is Part of the Flagellar Regulon. J. Bacteriol. 2000, 182, 2314-2320. [CrossRef] [PubMed]

46. Castelli, M.E.; Fedrigo, G.V.; Clementín, A.L.; Ielmini, M.V.; Feldman, M.F.; Véscovi, E.G. Enterobacterial common antigen integrity is a checkpoint for flagellar biogenesis in Serratia marcescens. J. Bacteriol. 2008, 190, 213-220. [CrossRef] [PubMed]

47. Fu, J.; Huang, H.; Meng, K.; Yuan, T.; Yao, B.; Shi, Y.; Ouyang, P. A novel cold-adapted phospholipase A 1 from Serratia sp. xjF1: Gene cloning, expression and characterization. Enzym. Microb. Technol. 2008, 42, 187-194. [CrossRef]

48. Dong, X.; Zhang, Y.J.; Zhang, Z. Using weakly conserved motifs hidden in secretion signals to identify type-III effectors from bacterial pathogen genomes. PLoS ONE 2013, 8, e56632. [CrossRef]

49. Givskov, M.; Molin, S. Expression of extracellular phospholipase from Serratia liquefaciens is growth-phase-dependent, catabolite-repressed and regulated by anaerobiosis. Mol. Microbiol. 1992, 6, 1363-1374. [CrossRef]

50. Anderson, M.T.; Mitchell, L.A.; Mobley, H.L. Cysteine biosynthesis controls Serratia marcescens phospholipase activity. J. Bacteriol. 2017, 199, e00159-17. [CrossRef]

51. Liao, W.X.; Moore, R.K.; Otsuka, F.; Shimasaki, S. Effect of intracellular interactions on the processing and secretion of bone morphogenetic protein-15 (BMP-15) and growth and differentiation factor-9. Implication of the aberrant ovarian phenotype of BMP-15 mutant sheep. J. Biol. Chem. 2003, 278, 3713-3719. [CrossRef]

52. Sun, J.; Zhuang, F.F.; Mullersman, J.E.; Chen, H.; Robertson, E.J.; Warburton, D.; Liu, Y.H.; Shi, W. BMP4 activation and secretion are negatively regulated by an intracellular gremlin-BMP4 interaction. J. Biol. Chem. 2006, 281, 29349-29356. [CrossRef] [PubMed]

(C) 2020 by the authors. Licensee MDPI, Basel, Switzerland. This article is an open access article distributed under the terms and conditions of the Creative Commons Attribution (CC BY) license (http://creativecommons.org/licenses/by/4.0/). 